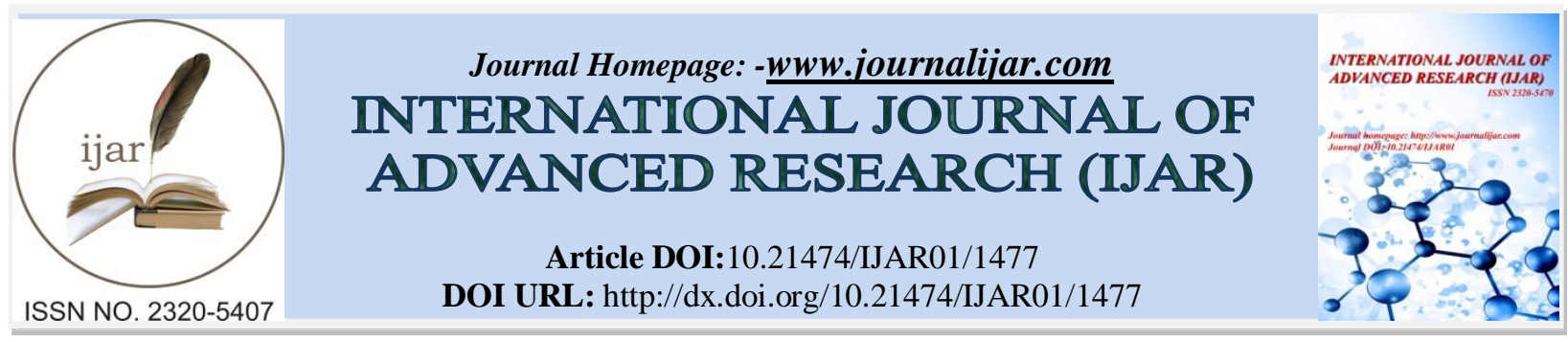

RESEARCH ARTICLE

\title{
AN ETIOLOGICAL STUDY OF ISCHEMIC STROKE IN YOUNG ADULTS.
}

AzzaAbassGhali, Ehab A El-Seidy, Sabry M Abdeldayem and Yasser A El-Heneedy. Department of Neuropsychiatry, Tanta University.

\section{Manuscript Info}

Manuscript History

Received: 16 July 2016

Final Accepted: 12 August 2016

Published: September 2016

Key words:-

Ischemic stroke, young adults, cardioembolic, traditional risk factors.

\section{Abstract}

Background:- Ischemic stroke in young adult accounts for up to $12 \%$ of all first ever ischemic strokes. Cardioembolic source has been shown to be the most frequent cause of ischemic stroke in young population.

Objective:-To determine the different etiologies and risk factors of ischemic stroke in young adults.

Patients and methods:-The present descriptive study was performed on 40 patients presented by cerebral ischemic stroke whose age was ranged between 20-42 years. After detailed history and examination, all patients underwent standard diagnostic investigations. The laboratory investigations included complete blood counts (CBC), ESR, urine examination, liver function tests, lipid profile and renal function tests. Thrombophilia screening and protein C\&S assay were performed in patients when indicated. Electrocardiogram (ECG), echocardiogram, carotid duplex ultrasound study, imaging studies of brain including CT scan and/or magnetic resonance imaging (MRI), were carried out routinely in all patients.

Results:-There was an overall female preponderance (F/M ratio 1.2/1). Cardioembolism was the most frequent cause of young stroke (32.5\%), followed by stroke due to large artery atherosclerosis (27.5\%). Small vessel disease (15\%), determined etiology (12.5\%) and stroke due to undetermined etiology $(12.5 \%)$ were least frequent etiologic patterns.Smoking, hypertension and dyslipidemia were statistically significantly associated risk factors in this series of younger stroke patients.

Conclusion:-Cardioembolic etiology is the most common treatable subtype of stroke in young adults and traditional risk factors i.e. hypertension, diabetes mellitus, dyslipidemia and cigarette smoking are the most important risk factors associated with ischemic stroke in young adults.

Copy Right, IJAR, 2016,. All rights reserved.

\section{Introduction:-}

Stroke in young adult is an important cause of morbidity and mortality throughout the world, especially in developing countries. The annual incidence rate of ischemic stroke in young adults has been reported to be 2-12 new cases per 100,000 per year around the globe ${ }^{1}$ with a higher frequency between 31 and 45 years $^{2}$.An estimated 3.5 million of the 5.5

Corresponding Author:-Azza Abass Ghali.

Address:-Department of Neuropsychiatry, Tanta University. 
million deaths from stroke occur in developing countries each year. ${ }^{3}$ Stroke in people under 45 years of age is less frequent than in older populations but has a major impact on the individual and society. ${ }^{4}$

TOAST classification system includes five subtypes of brain infarction:Large artery atherosclerosis stroke is due to significant stenosis or occlusion of a major brain artery, which is represented clinically by cerebral cortical impairment (e.g. aphasia, apraxia, restricted motor involvement).Cardioembolism occurs in patientswith arterial occlusion due to an embolus arising mainly from the heart. It is clinically similar to those of large artery atherosclerosis. Small artery occlusion stroke includes the patients who have one of the traditional clinical lacunar syndromes and don't have evidence of cerebral cortical dysfunction. Stroke of determined etiologies; this category consists of patients with rare causes of stroke such as non-atherosclerotic vasculopathies (e.g. internal carotid artery dissection, post-irradiation vasculopathies, fibromuscular dysplasia, arteritis), haematological disorders (Protein C or Protein S deficiency, antithrombin III deficiency, antiphospholipid syndrome) or coagulation disorders. Stroke of undetermined (SUD) etiologies is diagnosed if there are more than one cause identified such as atherothrombosis and cardioembolism and each one could be the cause. ${ }^{5}$

Recent studies reported that hypertension, diabetes mellitus, dyslipidemia and cigarette smoking emerged as important risk factors for stroke in young adults. ${ }^{6}$

The objective of this study was to determine the different etiologies and risk factors of ischemic stroke in young adults.

\section{Patients and methods:-}

The present descriptive study was performed on 40 patients presented by cerebral ischemic stroke whose age was ranged between 20-42 years. The patients included in this study were collected from the inpatient part of the Neuropsychiatry Department, Tanta University Hospital in the period from August 2011 to June 2012.

The patients were chosen consecutively with the following inclusion criteria:

- Patient's age ranged from 20 to 42 years.

- Stroke was diagnosed if patient had a neurological deficit lasting more than 24 hours with no other cause than vascular.

- Ischemic cerebral lesion was documented by CT and/or MRI brain.

Patients with any of the following criteria were excluded from the study:

- Transient ischemic attacks (TIA).

- Non-ischemic etiology such as hemorrhagic stroke or subarachnoid hemorrhage.

- Other neurological causes of acute focal cerebral dysfunction such as multiple sclerosis (MS), trauma and infection.

All patients were assessed according to the following scheme of clinical evaluation and investigations:

Detailed medical history with special attention to past medical history obtained from the patients or their relatives to establish the presence of any risk factor. ${ }^{7}$

- Hypertension: which was determined as those having previous diagnosis of hypertension, the use of antihypertensive medication, or whose systolic blood pressure was found to be $>140 \mathrm{mmHg}$ and/or diastolic blood pressure $>90 \mathrm{mmHg}$ on at least two occasions.

- Cardiac diseases were determined as those having previous clinical diagnosis with ECG and/or Echo abnormalities.

- Diabetes Mellitus was diagnosed when fasting blood glucose $>140 \mathrm{mg} / \mathrm{dl}$, postprandial $>180 \mathrm{mg} / \mathrm{dl}$ and/or presence of previous oral hypoglycemic medications or insulin use ${ }^{8}$.

- Hyperlipidemia was diagnosed if there was abnormal fasting lipid profile as defined by National Cholesterol Education Program (NCEP), (1993) criteria as follows:

- $\quad$ Total cholesterol $\geq 200 \mathrm{mg} / \mathrm{dL}$.

- Low density lipoprotein (LDL) "Bad cholesterol" $\geq 100 \mathrm{mg} / \mathrm{dL}$.

- High density lipoprotein (HDL) "Good cholesterol" of values $<40 \mathrm{mg} / \mathrm{dL}$.

- Hypertriglyceredemia more than $150 \mathrm{mg} / \mathrm{dL}$.

- Cigarette smoking was also defined as a risk factor when a patient has smoked $>10$ cigarettes per day for more than one year before stroke. ${ }^{9}$

- Detailed medical history regarding contraceptive pills, previous TIAs, blood diseases, drug intake, migraine and physical inactivity. 
2. Complete general examination, with stressing on cardiovascular system, and neck examination.

3. Complete neurological examination to define the anatomic site of the lesion and record the degree of disability.

4. Laboratory investigations:

- $\quad$ Complete blood count (CBC).

- Erythrocyte sedimentation rate (ESR).

- Fasting blood sugar (FBS).

- Lipid profiles including total cholesterol, triglycerides, HDL, and LDL.

- Kidney function tests including creatinine and urea.

- Liver function tests including total proteins, albumin, SGOT, and SGPT.

- Prothrombin time, concentration and international normalized ratio (PT, PC, and INR) and partial thromboplastin time (PTT).

- Protein $\mathrm{C}$ and protein $\mathrm{S}$ assay.

5. Electrocardiography (ECG).

6.Transthoracic echocardiography and transoesophageal echocardiography when needed.

7. Carotid Duplex.

8. Brain imaging:

- Cranial Computed Tomography (CT) was routinely carried out in all patients.

- Magnetic resonance imaging (MRI), magnetic resonance angiography (MRA) and magnetic resonance venography (MRV) of brain were carried out if needed in the studied patients.

\section{Statistical analysis:-}

Results of demographic characteristics, etiologic patterns and risk factors were analyzed using SPSS (Statistical Packages for Social Sciences) version 11.0. Chi-square test was used to compare the effect of modifiable risk factors on variants of young stroke.

\section{Results:-}

Total of 40 patients aged $20-42$ years were admitted with a diagnosis of ischaemic stroke over the period of one year. There was an overall female preponderance (F/M ratio 1.2/1). However, this ratio was not uniform throughout all stroke subtypes. Females outnumbered males in stroke due to cardioembolism and determined etiologies, whereas males outnumbered females in stroke due to large artery atherosclerosis, small vessel disease and undetermined etiologies.

Patients were subgrouped into two age groups. Majority of patients having evidence of cardioembolic source fell between 20 - 30 years of age while most of those with stroke due to large artery atherosclerosis and small vessel disease were found to be in advanced age groups of 31 years and above (Table I).

Cardioembolism was the most frequent cause of young stroke (32.5\%), followed by stroke due to large artery atherosclerosis (27.5\%). Small vessel disease (15\%), determined etiology (12.5\%) and stroke due to undetermined etiology $(12.5 \%)$ were least frequent etiologic patterns (Table II).

Among the cardiovascular sources, majority were due to rheumatic valvular heart disease (53.8\%) followed congenital heart diseases (23.1\%) i.e two patients with patent foramen oval and one patient with mitral valve prolapse. There were two patients with ischemic heart disease (15.4\%) and one patient with multiple cardiac lesions (7.7\%) i.e. atrial fibrillation and infective enocarditis (Table III).

In stroke of determined etiology, two patients had protein $\mathrm{C} \& \mathrm{~S}$ deficiency (40\%), two patients had systemic lupus erythematois (40\%) and one patient had rheumatoid arthritis (20\%).

Smoking, hypertension and dyslipidemia were statistically significantly associated risk factors in this series of younger stroke patients. However, diabetes mellitus was found to have insignificant association to any of the etiologic patterns of stroke (Table IV). 
Table I:-Demographic characteristics (age and gender) of patients $(n=40)$.

\begin{tabular}{|c|c|c|c|c|c|c|}
\hline & $\begin{array}{c}\text { Cardioemboli } \\
\mathrm{sm} \\
(\mathrm{n}=13)\end{array}$ & $\begin{array}{c}\text { Large artery } \\
\text { atherosclerosis } \\
(\mathrm{n}=11)\end{array}$ & $\begin{array}{c}\text { Small vessel } \\
\text { disease } \\
(\mathrm{n}=6)\end{array}$ & $\begin{array}{c}\text { Stroke due to } \\
\text { determined } \\
\text { etiology } \\
(\mathrm{n}=5)\end{array}$ & $\begin{array}{c}\text { Stroke due to } \\
\text { undetermined } \\
\text { etiology } \\
(\mathrm{n}=5)\end{array}$ & $\begin{array}{c}\mathrm{p}- \\
\text { value }\end{array}$ \\
\hline Agegroup & & & & $3(60 \%)$ & $2(40 \%)$ & \\
\hline $20-30$ & $9(69.2 \%)$ & $2(18.2 \%)$ & $1(16.7 \%)$ & $2(40 \%)$ & $3(60 \%)$ & 0.000 \\
\hline $31-42$ & $4(30.8 \%)$ & $9(81.8 \%)$ & $5(83.3 \%)$ & & & \\
\hline Gender & & & & $2(40 \%)$ & $2(40 \%)$ & 0.393 \\
\hline Male & $3(23.1 \%)$ & $7(63.6 \%)$ & $4(66.7 \%)$ & $3(60 \%)$ & $3(60 \%)$ & \\
\hline Female & $10(76.9 \%)$ & $4(36.4 \%)$ & $2(33.3 \%)$ & & & \\
\hline
\end{tabular}

Table II:-Distribution of causes of stroke in young adults.

\begin{tabular}{|l|c|c|}
\hline Causes & Number of patients & Percentage \\
\hline Cardioembolism & 13 & $32.5 \%$ \\
\hline Large artery atherosclerosis & 11 & $27.5 \%$ \\
\hline Small vessel disease & 6 & $15 \%$ \\
\hline Stroke due to determined etiology & 5 & $12.5 \%$ \\
\hline Stroke due to undetermined etiology & 5 & $12.5 \%$ \\
\hline Total & 40 & $100 \%$ \\
\hline
\end{tabular}

Table III:-Type of the lesion and cause of cardiac disorder.

\begin{tabular}{|l|c|c|}
\hline Type of lesion (cause) & Number of patients & \% \\
\hline Rheumatic valvular heart diseases & 7 & 23.8 \\
\hline Congenital heart diseases & 3 & 15.4 \\
\hline Ischemic heart diseases & 2 & 7.7 \\
\hline Multiple lesions & 1 & \\
\hline
\end{tabular}

Table IV:-Stroke of determined etiology

\begin{tabular}{|l|c|c|}
\hline Causes & Number of patients & $\%$ \\
\hline Protein C\&S defiency & 2 & 40 \\
\hline Systemic lupus erythematosis & 2 & 40 \\
\hline Rheumatoid arthritis & 1 & 20 \\
\hline
\end{tabular}

Table V:-Comparative analysis of modifiable risk factors in stroke subtypes in the studied patients.

\begin{tabular}{|c|c|c|c|c|c|c|}
\hline $\begin{array}{l}\text { Modifiable risk } \\
\text { factors }\end{array}$ & $\begin{array}{l}\text { Large artery } \\
\text { atherosclerosis/ } \\
\quad(\mathrm{n}=11)\end{array}$ & $\begin{array}{c}\text { Small } \\
\text { vessel } \\
\text { disease }\end{array}$ & $\begin{array}{l}\text { Stroke due to } \\
\text { determined } \\
\text { etiologv }\end{array}$ & $\begin{array}{c}\text { Stroke due to } \\
\text { undetermined } \\
\text { etiologv }\end{array}$ & p-value & $\begin{array}{l}\text { Odds } \\
\text { ratio }\end{array}$ \\
\hline Hypertension & $7(63.6 \%)$ & $3(50.0 \%)$ & $2(40 \%)$ & $2(40 \%)$ & $0.020 *$ & 4.35 \\
\hline Diabetes mellitus & $2(18.2 \%)$ & $2(33.3 \%)$ & $1(20 \%)$ & $1(20 \%)$ & 0.600 & 1.5 \\
\hline Dyslipidemia & $7(63.6 \%)$ & $4(66.7 \%)$ & $2(40 \%)$ & $3(60 \%)$ & $0.032 *$ & 3.64 \\
\hline Smoking & $5(45.5 \%)$ & $4(66.7 \%)$ & $1(20 \%)$ & $1(20 \%)$ & $0.056^{*}$ & 3.24 \\
\hline
\end{tabular}

* Statistically significant $(p<0.05)$.

\section{Discussion:-}

Stroke is a global health problem and an important cause of morbidity and mortality in young adults, especially in developing countries ${ }^{10}$. More than two-thirds of the global burden of stroke occurs in developing countries, where the average age of patients with stroke is 15 years younger than that in developed countries ${ }^{10,11}$. The present study was designed to determine the different etiologies and risk factors of ischemic stroke in young adults.

Although the risk of stroke is considered to be more frequent in men than women, except during menopausal period ${ }^{9,12}$, however the male preponderance for stroke declines in younger patients before the age of 30 years. It is more common in females by a factor of 1.5 to $3.0^{13}$. In our study $55 \%(22 / 40)$ of patients were women that were in agreement with studies from western countries which reported that cerebral infarction is common in young females. 
In this study, we found that the incidence of stroke increased with increasing age. Patients aged between 21-30 years comprised $42.5 \%$ (17/40), whereas patients aged $31-42$ years comprised $57.5 \%$ (23/40). This observation was similar to that obtained by Varonaet al. ${ }^{2}$ who reported a frequency of approximately $64 \%$ at age $36-45$ years.

In this study, cardioembolism was found to be the most frequent cause of acute ischaemic stroke (32.5\%) in young adults followed by stroke due to large artery atherosclerosis $(27.5 \%)$.

In comparison with the study by Nedeltchevet al. carried out at Switzerland, ${ }^{14}$ this study showed similarly high frequency of stroke due to cardioembolism and stroke due to undetermined etiology. When results were compared with study by Lipskaet al,${ }^{15}$ there was close resemblance in the frequency of etiologic subtypes.

There was higher frequency of stroke subtypes due to large artery atherosclerosis and small vessel disease in this study $(27.5 \%$ and $15 \%)$ as well as in an Indian study $(12 \% \text { and } 4 \%)^{16}$.

Among cardiovascular causes, rheumatic valvular heart disease was found to be the most frequent cause of acute ischaemic stroke, similar to the results found in South Indian as well as Helsinki study. ${ }^{6,15}$

Congenital patent foramen oval was the next frequent cause of cardioembolism in this series. While comparing with Bergen stroke study, ${ }^{17}$ a significant difference was found. Patent foramen oval was found to be the most frequent cause followed by mechanical heart valves in Bergen stroke study and rheumatic heart disease was conspicuously absent from the list of causes of young stroke. However, rheumatic heart disease was found to be the frequent cause of young ischaemic stroke in a Taiwanese study. ${ }^{18}$

In this series of patients, stroke due to determined etiology made up $12.5 \%$ of total number of cases. In this category, two patients had hematological disorders (40\%). One patient had protein C deficiency and the other patient had both protein C and $\mathrm{S}$ deficiency. Similar results were mentioned by Rosinget. al. ${ }^{19}$ who reported that activated protein $\mathrm{C}$ resistance recently has been recognized as a cause of a hypercoagulable state that has been found in $4 \%-7 \%$ of western European population. Martinez et $\mathrm{al}^{20}$ record 3 of his 50 young stroke patients $(6 \%)$ with protein $\mathrm{C}$ deficiency.

In this study the vasculopathy was the cause of stroke in 3 patients; two of them had systemic lupus erythematosis and the other had rheumatoid arthritis. Brinagorrementeriaet. al. ${ }^{21}$ reported that vasculopathy affecting 33 patients out of $130(25 \%)$ was the cause of cerebral infarction in young. The high percent can be explained by the presence of other causes of vasculopathy than discussed in our study as Takayasus arteritis. Watson et. al. $^{22}$ reported that rheumatoid disease is rarely complicated by a systemic vasculitis which can involve the brain. Devinsky et $\mathrm{al}^{23}$ reported that systemic lupus erythrematoasis can cause focal ischemic and sometimes hemorrhagic cerebral episodes or strokes mostly arterial but sometimes venous.

Observation of the current study suggested the association of the traditional risk factors like hypertension, diabetes mellitus, smoking, dyslipidaemia, heart disease with stroke in the young adults. This was supported by many studies from Saudi population ${ }^{24,25}$, Qatar $^{26}$ and Turkey ${ }^{9}$ as they reported the predominance of traditional risk factors of stroke in young adults.

The high frequencies of modifiable risk factors in this study indicate a need for primary and secondary precaution strategies in young adults.

\section{Conclusion:-}

This study gives insight into the significance of potentially preventable and treatable etiologies like rheumatic heart disease as a cause of stroke in younger patients. The study also provides valuable information about role of traditional risk factors in young stroke patients.

\section{References:-}

1. Jacobs BS, Boden-Albala B, Lin I-F and Sacco RL: Stroke in the young in the Northern Manhattan Stroke Study. Stroke2002; 33: 2789-2796.

2. Varona JF, Guerra JM, Bermejo F, Molina JA and Gomez de la Cámara A: Causes of ischemic stroke in young Adults, and evolution of the etiological diagnosis over the long term. EurNeurol 2007; 57: 212-218. 
3. World Health Organisation. The world health report. Geneva: WHO; 2000.

4. Griffiths D, Sturm J. Epidemiology and etiology of young stroke. Stroke Res Treat 2011; 2011:209370.

5. Adams HP Jr, Bendixen BH, Kappelle LJ, Biller J, Love BB, Gordon DL, et al. Classification of subtype of acute ischaemic stroke. Definitions for use in a multicenter clinical trial. TOAST: trial of Org 10172 in acute stroke treatment. Stroke 1993; 24:35-41.

6. Putaala J, Metso AJ, Metso TM, Konkola N, Kraemer Y, Haapaniemi E, Kaste M and Tatlisumak T: Analysis of 1008 Consecutive Patients Aged 15 to 49 With First-Ever Ischemic Stroke: The Helsinki Young Stroke Registry. Stroke 2009; 40; 1195-1203.

7. Leoo T, Lindgren A, Petersson J and von Arbin M: Risk Factors and Treatment at Recurrent Stroke Onset: Results from the Recurrent Stroke Quality and Epidemiology (RESQUE) Study. Cerebrovasc Dis 2008; 25: 254260.

8. Ganesan V, Prengler M, McShane MA, Wade AM, Kirkham FJ: Investigation of risk factors in children with arterial ischemic stroke; Ann Neurol2010; 53:167-173.

9. Benbir G, Uluduz D, Ince B and Gunduz A: Clinical Characteristics and Risk Factors In Young Stroke. Egal J Intern Med 2007; 1: 1-14.

10.Pandian JD, Padma V, Vijaya P, Sylaja PN and Murthy JM: Stroke and thrombolysis in developing countries Journal compilation. Int J Stroke 2007; 2: 17-26.

11. Bonita R, Mendis S, Truelsen T, Bogousslavsky J, Toole J and Yatsu F: The global stroke initiative. Lancet Neurol 2004; 3: 391-393.

12. Erhardt LR: Women neglected risk group for atherosclerosis and vascular disease. ScandCardiovasc J 2003; 37 : 3-12.

13. Rasura M, Spalloni A, Ferrari M, De Castro S, Patella R, Lisi F and Beccia M: A case series of young stroke in Rome. Eur J Neurol2006; 13: 146-152.

14. Nedeltchev K, der Maur TA, Georgiadis D, Arnold M, Caso V, Mattle HP, et al. Ischaemic stroke in young adults: predictors of outcome and recurrence. J NeurolNeurosurg Psychiatry 2005; 76:191-5.

15.Lipska K, Sylaja PN, Sarma PS, Thankappan KR, Kutty VR, Vasan RS, et al. Risk factors for acute ischaemic stroke in young adults in South India. J NeurolNeurosurg Psychiatry 2007; 78:959-63.

16. Mehndiratta MM, Agarwal P, Sen K, Sharma B. Stroke in young adults: a study from a university hospital in North India. Med SciMonit 2004; 10:535-41

17. Fromm A, Waje-Andreassen U, Thomassen L, Naess H. Comparison between ischaemic stroke patients $<50$ years and $\geq 50$ years admitted to a single centre: the Bergen Stroke study. Stroke Res Treat 2011; 2011:183256.

18. Lee TH, Hsu WC, Chen CJ, Chen ST. Etiologic study of young ischaemic stroke in Taiwan. Stroke 2002; 33:1950-5.

19. Rosing J, TansG, Nicolaes GAF et al: oral contraceptive and venous hrombosis: different sensitivties to activated protein $\mathrm{C}$ in women using second -and third generation oral contraceptive Br J Heamatol 2001; 97:233238.

20. Martinez M.R; Rangel-Guerra R.A; Morfil L.J: Ischemic stroke due to deficiency of coagulation inhibitors. Report of 10 young adults. Stroke 2005; $24: 19-25$.

21.Barinagarrementeria,Gonzalez-Durte, Miranda cantu: Cerebral infarction of young women analysis of 130 cases EurNeurol 2003; 40: 228-233.

22. Watson P, Fekeie J. And Deck J : Central nervous system vasculitis in rheumatoid arthiritis can J neurol. Sci 2005; 4, 219-72.

23.Devinsky, O; Petito, C.K.; and Alonso, D.R.: Clinical and neuropathological finding in systemic lupus erthrymatosus: role of vasculitis, heart emboli, and thrombtic thrombocytopenic purpura. ANN. Neurol 2001, $23,380-4$.

24. Al-Muaygil and Khoja W: Ischemic stroke in young Saudis: 2-year RKH experience. Neurosciences 2003; 8 (1): 48-48.

25. Arulneyam J, Shobhit S, Siddiqui KA and Al-Senani F: An observational study of "stroke in young". Neurosciences 2008; 13 (1): 10-10.

26. Khan FY: Risk factors of young ischemic stroke in Qatar. ClinNeurolNeurosurg 2007; 109: 770-773. 